\title{
Stress during a Critical Postnatal Period Induces Region-Specific Structural Abnormalities and Dysfunction of the Prefrontal Cortex via CRF,
}

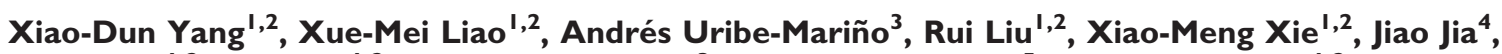 \\ Yun-Ai Su ${ }^{1,2}$, Ji-Tao Li ${ }^{1,2}$, Mathias V Schmidt ${ }^{3}$, Xiao-Dong Wang*,5 and Tian-Mei Si*, 1,2 \\ IInstitute of Mental Health, Peking University, Beijing, China; ${ }^{2}$ Key Laboratory of Mental Health, Ministry of Health (Peking University), Beijing, \\ China; ${ }^{3}$ Department of Stress Neurobiology and Neurogenetics, Max Planck Institute of Psychiatry, Munich, Germany; ${ }^{4}$ Department of Mental \\ Health, Dayi Hospital Affiliated to Shanxi Medical University, Taiyuan, China; ${ }^{5}$ Department of Neurobiology, Key Laboratory of Medical \\ Neurobiology of Ministry of Health of China, Zhejiang Province Key Laboratory of Neurobiology, Zhejiang University School of Medicine, \\ Hangzhou, China
}

\begin{abstract}
During the early postnatal period, environmental influences play a pivotal role in shaping the development of the neocortex, including the prefrontal cortex (PFC) that is crucial for working memory and goal-directed actions. Exposure to stressful experiences during this critical period may disrupt the development of PFC pyramidal neurons and impair the wiring and function of related neural circuits. However, the molecular mechanisms of the impact of early-life stress on PFC development and function are not well understood. In this study, we found that repeated stress exposure during the first postnatal week hampered dendritic development in layers $\|/\| I$ and $V$ pyramidal neurons in the dorsal agranular cingulate cortex (ACd) and prelimbic cortex (PL) of neonatal mice. The deleterious effects of early postnatal stress on structural plasticity persisted to adulthood only in ACd layer $V$ pyramidal neurons. Most importantly, concurrent blockade of corticotropin-releasing factor receptor I (CRF $)$ by systemic antalarmin administration (20 $\mu \mathrm{g} / \mathrm{g}$ of body weight) during early-life stress exposure prevented stress-induced apical dendritic retraction and spine loss in ACd layer $V$ neurons and impairments in PFC-dependent cognitive tasks. Moreover, the magnitude of dendritic regression, especially the shrinkage of apical branches, of ACd layer $\checkmark$ neurons predicted the degree of cognitive deficits in stressed mice. Our data highlight the region-specific effects of early postnatal stress on the structural plasticity of prefrontal pyramidal neurons, and suggest a critical role of CRF, in modulating early-life stress-induced prefrontal abnormalities.

Neuropsychopharmacology (2015) 40, 1203-1215; doi:I0.1038/npp.2014.304; published online I0 December 20I4
\end{abstract}

\section{INTRODUCTION}

The prefrontal cortex (PFC), a highly evolved neocortical region essential for executive functions, is particularly sensitive to the detrimental effects of stress (McEwen and Morrison, 2013). Repeated exposure to severe stress in critical developmental stages, especially during the early childhood, may disrupt PFC development and impair working memory later in life (Evans and Schamberg, 2009; Hanson et al, 2012). Accumulating evidence demonstrates that early-life stress is one of the major risk factors for psychiatric disorders, including schizophrenia, depres-

*Correspondence: Dr X-D Wang, Department of Neurobiology, Zhejiang University School of Medicine, 310058 Hangzhou, China, Tel: +86 57| 88208506, Fax: +86 57I 88208640,

E-mail: dr.xiaodong.wang@gmail.com or Professor T-M Si, Institute of Mental Health, Peking University, No. 5I, Hua Yuan Bei Road, 100191 Beijing, China, Tel: +86 I0 82801948, Fax: +86 10 62352880,

E-mail: si.tian-mei@l63.com

Received II August 2014; revised 7 November 2014; accepted 13 November 2014; accepted article preview online 18 November 2014 sion, and anxiety disorders (Bradley et al, 2008; Cutajar et al, 2010; Nugent et al, 2011) that are associated with prefrontal dysfunction (Goto et al, 2010) and structural abnormalities (Black et al, 2004).

The rodent neocortex, including the medial PFC (mPFC), expands at a dramatic speed that exceeds the rates of most other brain structures in the first postnatal week (Zhang et al, 2005). During this critical developmental period, the lamination of mPFC is yet to be completed (Van Eden and Uylings, 1985). Dopaminergic fibers and afferents from the mediodorsal thalamic nucleus and amygdala invade the layers of $\mathrm{mPFC}$ and increase in density (Kalsbeek et al, 1988; Van Eden, 1986; Verwer et al, 1996). Meanwhile, the pyramidal neurons undergo extensive dendritic outgrowth, spine formation, synaptogenesis, and functional modifications (Miller, 1981; Portera-Cailliau et al, 2003; Zhang, 2004) that can be remodeled by early experiences (Holtmaat and Svoboda, 2009). As shown by previous studies, postnatal stress exposure impairs the development of $\mathrm{MPFC}$ neurons and mPFC-dependent cognitive performance in adolescent and adult animals (Bock et al, 2005; Chocyk et al, 2013; 
Monroy et al, 2010). However, although glucocorticoids (Wellman, 2001), glutamatergic neurotransmission (Martin and Wellman, 2011), and protein kinase C (PKC) (Hains et al, 2009) have been proposed to mediate the adverse effects of chronic adult stress on the structure and function of mPFC, a comprehensive insight into the mechanisms underlying early-life stress-evoked prefrontal abnormalities is still lacking.

Recently, we and others reported the crucial role of corticotropin-releasing factor (CRF) and its type 1 receptor $\left(\mathrm{CRF}_{1}\right)$ in modulating the negative effects of early-life stress on the development and plasticity of the hippocampus (Ivy et al, 2010; Liao et al, 2014; Wang et al, 2011; Wang et al, 2013). Because CRF- and $\mathrm{CRF}_{1}$-expressing neurons are found in mPFC (Alon et al, 2009; Kühne et al, 2012), this system may also modulate the effects of early-life stress on the development of mPFC pyramidal neurons and prefrontal function.

In this study, we aimed to determine the features and mechanisms of early postnatal stress-induced structural alterations of $\mathrm{MPFC}$ pyramidal neurons and their behavioral consequences. Here we applied a naturalistic mouse model of early-life stress, where an impoverished early environment is created by providing the dams with reduced nesting and bedding material from postnatal day 2 (P2) to P9 of their litter (Rice et al, 2008). This limited nesting and bedding material procedure has been shown to reduce the quality of maternal care and provoke prominent and lasting molecular, morphological, and behavioral alterations in the offspring (Molet et al, 2014), and has been used to uncover the involvement of $\mathrm{CRF}_{1}$ in early-life stressinduced anxiety-related behavior and hippocampal dysfunction (Ivy et al, 2010; Wang et al, 2012; Wang et al, 2011). Using this model and thus restricting the time window of stress exposure to the first postnatal week, the short- and long-term effects of stress during this critical period on the morphological development of layers II/III and $\mathrm{V}$ pyramidal neurons in the $\mathrm{mPFC}$ were characterized. Furthermore, the potential role of $\mathrm{CRF}_{1}$ in modulating postnatal stress-induced structural changes and memory deficits was evaluated using the $\mathrm{CRF}_{1}$ antagonist antalarmin.

\section{MATERIALS AND METHODS}

\section{Animals and Housing}

Twelve-week-old male and female C57BL/6 mice (Vital River Laboratories, Beijing, China) were used for breeding. After habituation in the vivarium, each female was housed with one male for 2 weeks and then single housed. Pregnant females were monitored daily for pup delivery at 0900 to $1000 \mathrm{~h}$, and the day of parturition was defined as P0. Only male offspring were used in the experiments.

All mice were housed under a 12-h light/dark cycle (lights on at $0800 \mathrm{~h})$ and constant temperature $\left(23 \pm 1^{\circ} \mathrm{C}\right)$ conditions with free access to both food and water. The experiments were approved by the Peking University Committee on Animal Care and Use and performed in compliance with the National Institute of Health's Guide for the Use and Care of Laboratory Animals.

\section{Early-Life Stress Procedure}

The limited nesting and bedding material paradigm was carried out according to an established protocol (Rice et al, 2008; Wang et al, 2011). On the morning of P2, pups were weighed and litters culled to 6-8 pups with equal numbers of males and females whenever possible. Control dams were provided with a sufficient amount of nesting material (2 squares ( $4.8 \mathrm{~g}$ ) of Nestlets, Indulab, Gams, Switzerland) and $500 \mathrm{ml}$ of standard sawdust bedding. In the 'stress' cages, dams were provided with a limited quantity of nesting material ( $1 / 2$ square $(1.2 \mathrm{~g})$ of Nestlets), placed on a fine-gauge aluminum mesh platform (McNichols, Tampa, FL, USA). The stress manipulation ended on the morning of P9.

\section{Experimental Design}

In experiment 1, the effects of early-life stress on morphological development of layers II/III and V pyramidal neurons in the dorsal agranular cingulate cortex (ACd) and the prelimbic cortex (PL), which are the major subdivisions of the dorsomedial and ventromedial PFC respectively, were examined (Figure 1a). Immediately after the stress procedure (P9), some of the pups were killed by decapitation and brains processed for morphological analysis. The other litters of pups were transferred to standard cages, weaned on P28, and killed in adulthood (P74-P78) for structural analysis. Experiments 2 (Figure $3 \mathrm{a}$ ) and 3 (Figure 5a) examined the effects of systemic $\mathrm{CRF}_{1}$ blockade on early-life stress-induced structural abnormalities and cognitive impairments respectively. Pups received daily vehicle or antalarmin injections during the stress procedure. In experiment 2, pups were either decapitated after stress ended (P9) for the analysis of glucocorticoid receptor (GR) and mineralocorticoid receptor (MR) protein levels and neuronal morphology, or killed in adulthood (P70-P77) for the analysis of dendrites and spines. In experiment 3 , all groups of mice were tested for anxiety-related behavior, spatial working memory, and temporal order memory in adulthood (P72-P79). At $24 \mathrm{~h}$ after behavioral tests, mice were killed for morphological assessment and correlation analysis. Because learning experience may induce rapid structural reorganizations of dendritic spines, whereas the dendritic arborizations of cortical pyramidal neurons are relatively stable (Holtmaat and Svoboda, 2009), we only focused on dendritic morphology in experiment 3. In all experiments, mice of each group were obtained from 3 to 5 litters. All mice were weighed at P2, P9, P28, P42, P56, and P70.

\section{Assessment of Maternal Behavior}

See Supplementary Information for details.

\section{Drug Treatment}

Drug administration was performed at 0900 to $1200 \mathrm{~h}$ on P2-P8. In experiments 2 and 3, control or stressed pups received a daily subcutaneous injection of vehicle (polyethylene glycol) or antalarmin hydrochloride ( $20 \mu \mathrm{g} / \mathrm{g}$ of body weight; Tocris Bioscience, Bristol, UK). 
a Experiment 1

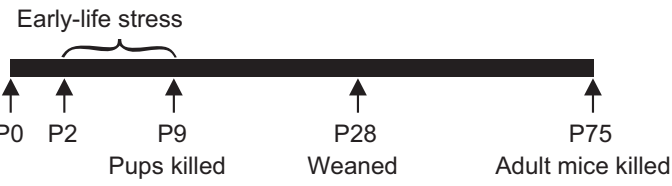

b

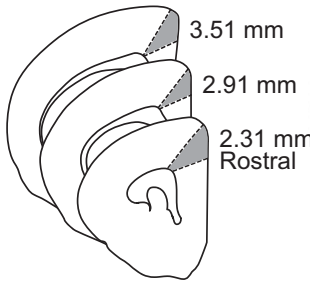

P9-Layer V

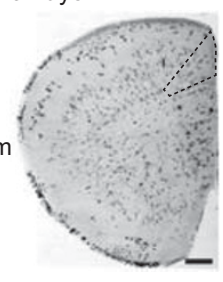

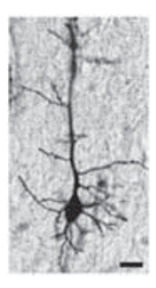

f

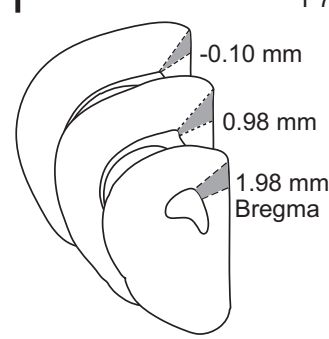

g

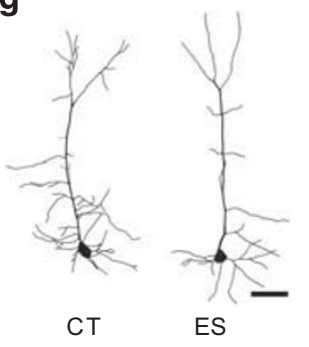

P75-Layer V

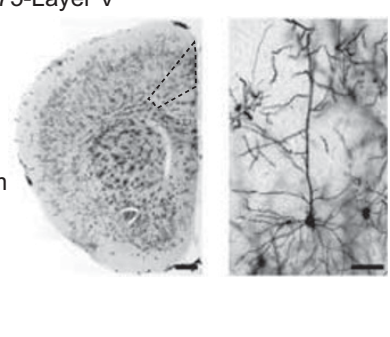

C

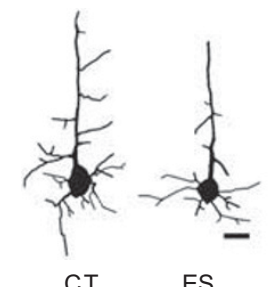

d

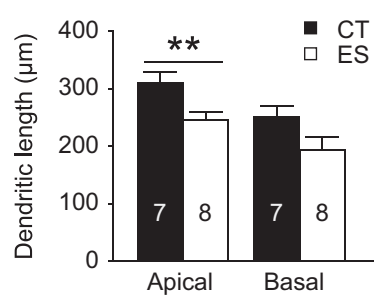

e

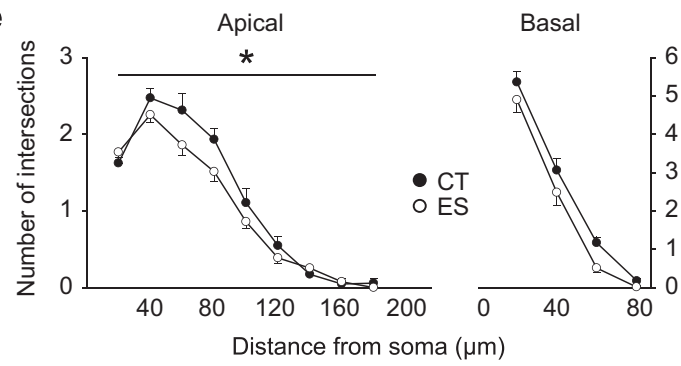

h

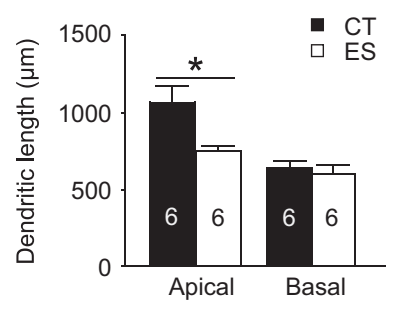

Basal

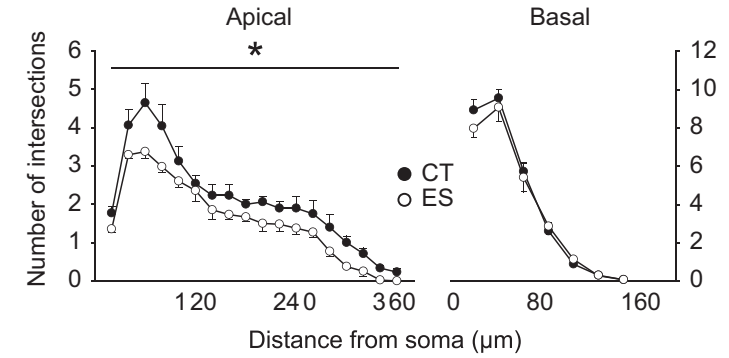

Figure I Effects of early-life stress on dendritic development of layer $\vee$ pyramidal neurons in the dorsal agranular cingulate cortex (ACd). (a) Schematic of the design of experiment I. (b) Diagrams of coronal sections (left) showing the region of interest (shaded areas), a Golgi-stained coronal section (middle; scale bar $=500 \mu \mathrm{m}$ ) taken through the level of ACd (dashed area), and a Golgi-impregnated ACd layer V pyramidal neuron from a 9-day-old pup (right; scale bar $=20 \mu \mathrm{m})$. (c) Representative Neurolucida tracings of ACd layer $\vee$ pyramidal neurons from control (CT) and early-life stressed (ES) pups. Scale bar $=20 \mu \mathrm{m}$. (d, e) Early-life stress reduced the length (d) and complexity (e) of apical but not basal dendrites of ACd layer $V$ pyramidal neurons in neonatal mice. (f) Diagrams of coronal sections (left) showing the region of interest (shaded areas), a Golgi-stained coronal section (middle; scale bar $=500 \mu \mathrm{m}$ ) taken through the level of ACd (dashed area), and a Golgi-impregnated ACd layer $\vee$ pyramidal neuron from an adult mouse (right; scale bar=50 $\mu m$ ). (g) Representative tracings of ACd layer $V$ pyramidal neurons in adult mice. Scale bar $=50 \mu \mathrm{m}$. (h, i) The length (h) and complexity (i) of apical but not basal dendrites were reduced in postnatally stressed adult mice. ${ }^{*} p<0.05$, ${ }^{*} * x<0.01$. In this and subsequent figures, the number of animals in each group is indicated in the bar graphs.

The dosage choice was based on previous studies (Liao et al, 2014; Rissman et al, 2012). Before the injection, the home cage containing the litter was placed on a heating pad maintained at $30-33^{\circ} \mathrm{C}$. The dam was then removed from the litter and transferred to a clean cage. Within each litter, 1-3 male pups were randomly assigned to each drug treatment group. Pups were marked on the paw pads with a maker pen, weighed, and injected with the solution $(5 \mu \mathrm{l} / \mathrm{g}$ of body weight) into the nape of the neck. The duration of injection was $<15 \mathrm{~min}$ per litter. After the injection, the dam was placed back to the home cage and the litters remained undisturbed for the next $24 \mathrm{~h}$.

\section{Golgi-Cox Staining and the Analysis of Dendrites and Spines}

Neonatal and adult brains were immersed in the Golgi-Cox solution for 9 and 14 days, respectively, and then transferred to $30 \%$ sucrose solution for 2-5 days in the dark at room temperature. Serial coronal sections $(120 \mu \mathrm{m})$ were prepared using a Microm HM 650V vibratome (Thermo Scientific, Walldorf, Germany), mounted on Superfrost plus slides (Thermo Scientific) and processed as described previously (Liao et al, 2014).

Darkly and consistently stained pyramidal neurons in layers II/III and V of ACd (Figure $1 \mathrm{~b}$ and $\mathrm{f}$ ) and PL (Paxinos 
et al, 2007; Van De Werd et al, 2010) were selected for structural analysis (ACd: 8-11 neurons for each layer per animal; PL: 3-8 neurons for each layer per animal). Neurons were traced at $\times 400$ with the Neurolucida software (MicroBrightField Bioscience, Williston, VT, USA), and Sholl analysis was performed to measure total dendritic length, the number of intersections at concentric circles $(20 \mu \mathrm{m}$ apart), and the number of branch points using the NeuroExplorer software (MicroBrightField). In experiments 2 and 3, the neuron morphology files generated by Neurolucida were converted to the SWC format by NLMorphologyViewer (http://www.neuronland.org/NL.html) and imported to the NeuronStudio software (http:// research.mssm.edu/cnic/tools-ns.html). The length of apical main dendrite (the large apical dendrite that connects the soma to distal tuft dendrites) and apical branches (including all oblique dendrites that emanate from the apical main dendrite at various angles and tuft dendrites) (Spruston, 2008) was measured respectively by NeuronStudio.

For dendritic spine analysis of ACd layer V pyramidal neurons, the inclusion criteria were as follows: (1) the apical main or oblique dendritic segments initiated at $80 \mu \mathrm{m}$ (for P9 neurons) or $120 \mu \mathrm{m}$ (for P75 neurons) from the soma and the distal basal dendrites were selected; (2) the length of selected segments was longer than $30 \mu \mathrm{m}$; (3) the diameters of selected segments for each dendritic domain were comparable; and (4) the segment did not overlap with other segments that would obscure visualization of spines. Bright-field $z$-series images of dendritic segments (8 segments for each dendritic domain per animal) were acquired at $\times 1000$ using a CoolSNAP MP5 CCD (Roper Scientific, Tucson, AZ, USA) fitted to an Olympus BX51 microscope (Olympus, Tokyo, Japan). Dendritic spines were categorized as thin, stubby, and mushroom types (Harris et al, 1992), and manually counted using the NIH ImageJ software by an investigator blind to the experimental conditions. Spine density was expressed as the number of spines per $10 \mu \mathrm{m}$ of dendrite.

In experiment 2 , the length and head diameter of dendritic spines whose long axes paralleled the imaging planes were measured by ImageJ. Spines that protruded in back or in front of optical planes were excluded from analysis because of the poor $z$-resolution of bright-field microscopy.

\section{Western Blot}

See Supplementary Information for details.

\section{Behavioral Testing}

Mice were singly housed at 1 week before testing. The following tests were conducted between 0900 and $1600 \mathrm{~h}$ and scored by ANY-maze 4.98 (Stoelting, Wood Dale, IL, USA).

Open field and light-dark box. See Supplementary Information for details.

Y-maze. The Y-maze apparatus was made of gray polyvinyl chloride with three symmetrical arms $(30 \times 10 \times$ $15 \mathrm{~cm}^{3}$ ) and illuminated at 30 lux. Mice were placed in the end of one arm and allowed to explore freely for $8 \mathrm{~min}$.
The total distance traveled, number of arm entries, spontaneous alternation ratio (Wang et al, 2013), and same arm return ratio (Wall and Messier, 2002; Wietrzych et al, 2005) were measured.

Temporal order memory test. In a pilot experiment, preference to the two objects (a $5 \times 5 \times 5 \mathrm{~cm}^{3}$ cube and a 5 -cm-diameter, 5 -cm-high cylinder, both made of aluminum) used in the temporal order memory test was determined by presenting the two objects to a separate cohort of treatmentand test-naive adult male C57BL/6 mice $(n=12)$ in the standard cages for $10 \mathrm{~min}$. The time spent exploring each object was recorded, and no object preference was noticed $\left(26.08 \pm 4.77\right.$ vs $\left.23.76 \pm 2.87 \mathrm{~s}, t_{11}=0.543, p=0.598\right)$. The temporal order memory test was performed in the open field arena under low illumination (10 lux) as previously described (Barker et al, 2007) with minor modifications. Before testing, mice were habituated to the testing environment for $2 \mathrm{~min}$ on 2 consecutive days. The testing procedure consisted of three consecutive sessions separated by intertrial intervals of $60 \mathrm{~min}$. In sample phases 1 and 2, two cubes and two cylinders were placed in the open field arena respectively. In the retrieval phase, one cube (the 'remote' object) and one cylinder (the 'recent' object) were presented. In each session, the animals were allowed to explore the objects for $10 \mathrm{~min}$, and the time spent exploring each object was measured.

\section{Statistical Analysis}

SPSS 16.0 (SPSS, Chicago, IL, USA), GraphPad Prism 5.0 (GraphPad Software, San Diego, CA, USA), and R version 2.15 (http://www.r-project.org/) were used to perform statistical analyses. Student's $t$-test was used to compare pairs of means. In experiment 1 , the number of dendritic intersections and body weight were analyzed by one-way repeated measures analysis of variance (ANOVA). In experiments 2 and 3, the number of branch points, dendritic length, spine density, protein levels, and behavior were analyzed by two-way ANOVA (stress $\times$ treatment) followed by Bonferroni post hoc test when a significant interaction was observed; maternal behavior, body weight, and number of dendritic intersections were analyzed by two-way repeated measures ANOVA. For spine size analyses in experiment 2, data were rank and Box-Cox transformed to achieve a normal data distribution, and the transformed data were analyzed by two-way ANOVA followed by Tukey's post hoc test when appropriate. In experiment 3, correlations between cognitive performance and dendritic length were assessed by Pearson's correlation coefficient. Statistical outliers with values that fell beyond $2 \mathrm{SD}$ values from the mean were excluded in the final statistical analysis. Data are reported as mean \pm SEM. Statistical significance was defined at $p<0.05$.

\section{RESULTS}

\section{Persistent Effects of Early-Life Stress on Apical Dendritic Development of ACd Layer V Pyramidal Neurons}

After exposure to stress during the first postnatal week (Figure 1a), the outgrowth of apical, but not basal, dendrites of ACd layer V pyramidal neurons in 9-day-old pups was 
markedly impaired (Figure 1b-e). Compared with the controls, the length and complexity of apical dendrites in stressed pups were significantly reduced (length: $t_{13}=3.299$, $p=0.006$; complexity: $F_{1,13}=4.973, p=0.044$ ). As adults, postnatally stressed mice still had fewer apical dendritic arborizations in layer $\mathrm{V}$ pyramidal neurons than the controls (length: $t_{5.612}=3.035, \quad p=0.025$; complexity: $\left.\mathrm{F}_{1,10}=8.576, p=0.015\right)$, indicating that the stress effects on this neuronal population are long lasting (Figure 1f-i). In comparison, the deleterious effects of early-life stress on apical dendritic development of ACd layer II/III pyramidal neurons were only evident in neonatal (length: $t_{13}=2.417$, $p=0.031$; complexity: $F_{1,13}=5.948, p=0.03$ ) but not adult mice (Supplementary Figure S1). In addition, in stressed pups, dendritic length of layers II/III and V pyramidal neurons in the PL region was also significantly reduced. However, early-life stress hampered dendritic branching only in PL layer V but not layer II/III neurons at P9, and these effects did not persist to adulthood (Supplementary Figure S2). Because the persistent effects of early-life stress on dendritic morphology were brain region and layer specific, we then focused on ACd layer V pyramidal neurons in the following experiments.
Early-Life Stress Lastingly Impairs Dendritic Spine Plasticity of the Apical Dendrites of ACd Layer V Pyramidal Neurons

Spine density in ACd layer V pyramidal neurons was quantified immediately after stress exposure or in adulthood to evaluate the short- and long-term effects of postnatal stress on spine formation and plasticity (Figure 2a and d). In stressed pups, spine density on apical oblique dendrites was significantly reduced $\left(t_{12}=3.446, p=0.005\right.$; Figure $2 \mathrm{~b}$ ), with the negative stress effects more pronounced on thin $\left(t_{12}=2.702, p=0.019\right)$ and mushroom spines $\left(t_{12}=2.258, p=0.043\right.$; Figure $\left.2 c\right)$. In adult mice with early stressful experience, the number of spines was decreased on both apical main $\left(t_{5.193}=3.971, p=0.01\right)$ and oblique dendrites $\left(t_{10}=4.092, p=0.002\right.$; Figure $\left.2 \mathrm{e}\right)$, and the effects were more evident on thin and mushroom spines (mainthin: $t_{5.247}=3.162, p=0.023$; mushroom: $t_{10}=2.853$, $p=0.017$; oblique-thin: $t_{10}=3.215, p=0.009$; Figure 2f). In contrast, spine density on basal dendrites in neonatal and adult mice was not affected by stress. These results indicate that early postnatal stress lastingly impairs the development and plasticity of dendritic spines, especially thin and

d
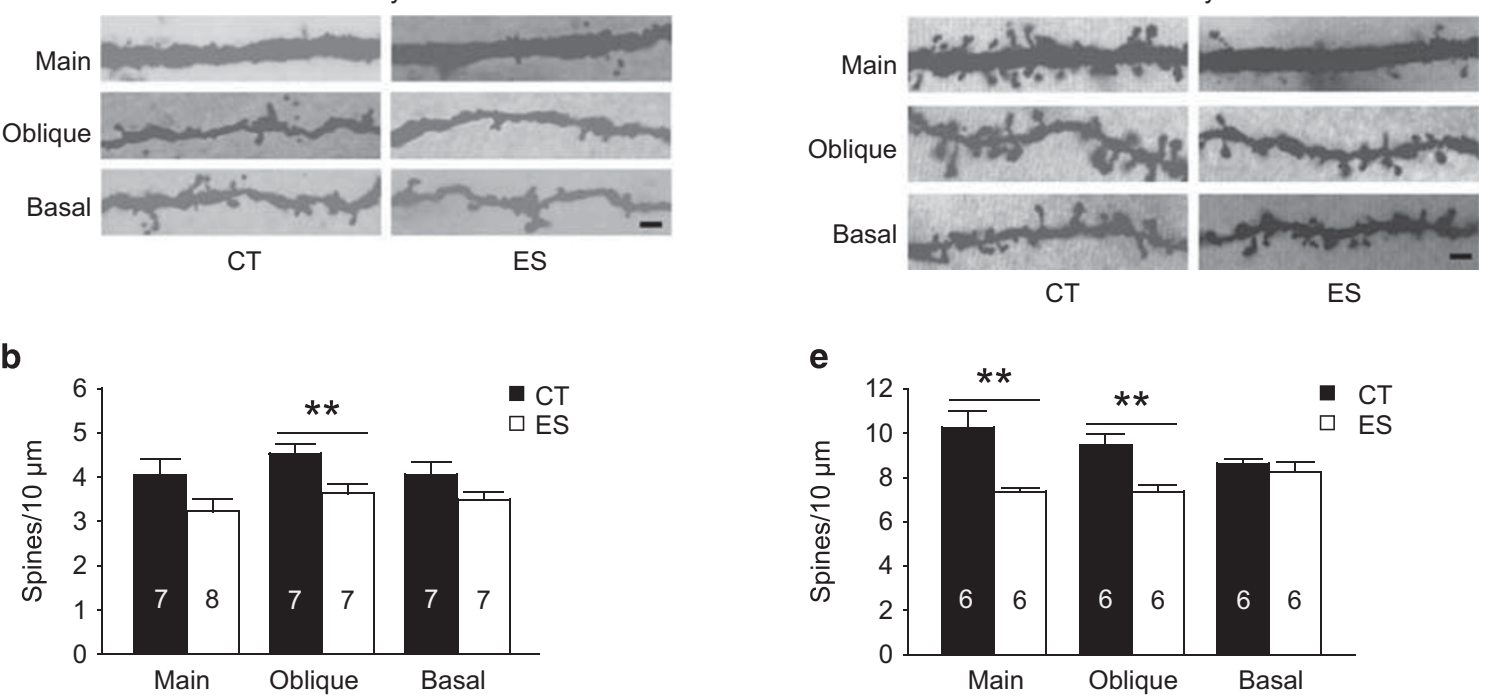

C

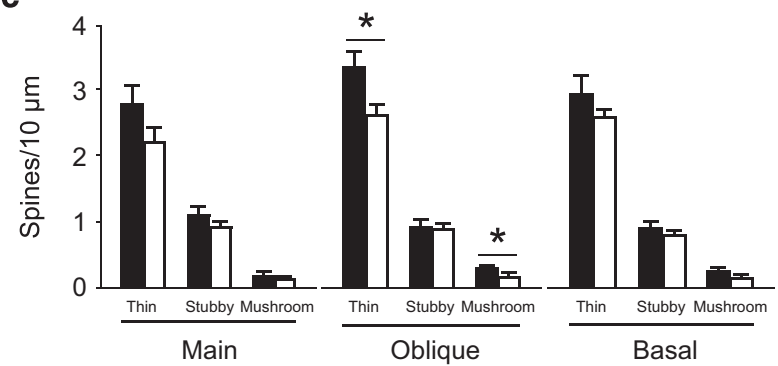

e

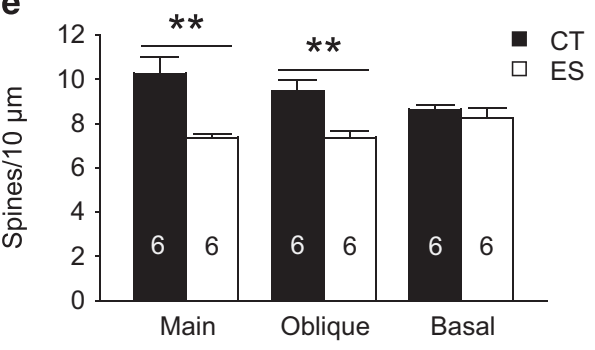

$\mathbf{f}$

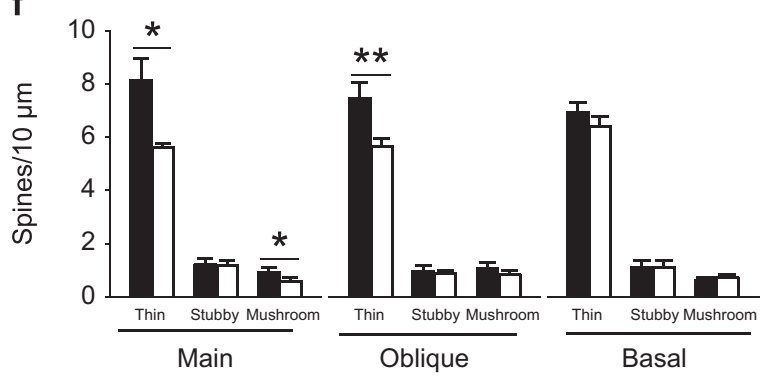

Figure 2 Short- and long-term effects of early-life stress on dendritic spine density of ACd layer $\vee$ pyramidal neurons. (a) Representative photomicrographs of apical main, apical oblique, and basal dendrites of ACd layer $\vee$ pyramidal neurons in P9 pups. Scale bar $=2 \mu \mathrm{m}$. (b) Early-life stress specifically reduced the number of spines on apical oblique dendrites in the neonatal pups. (c) The stress effects were more pronounced on thin and mushroom spines. (d) Photomicrographs of apical main, apical oblique, and basal dendrites of ACd layer $V$ pyramidal neurons in adult mice. Scale bar $=2 \mu \mathrm{m}$. (e) In stressed adult mice, spine density on apical main and oblique dendrites was significantly reduced. (f) Early-life stress evoked a loss of thin and mushroom spines on apical main dendrites and a reduction in thin spines on oblique dendrites. $* p<0.05, * * p<0.01$. 
mushroom spines, on the apical dendrites of ACd layer V pyramidal neurons.

\section{Blockade of $\mathrm{CRF}_{1}$ Attenuates Early-Life Stress-Evoked Dendritic Regression and Spine Loss in ACd Layer V Pyramidal Neurons}

To examine the potential role of $\mathrm{CRF}_{1}$ in postnatal stressinduced structural abnormalities in the mPFC, pups received daily antalarmin or vehicle injections during stress exposure (Figure 3a). Dams provided with limited nesting and bedding material exhibited disrupted maternal behavior as indicated by increased number of dam sorties $\left(\mathrm{F}_{1,12}=54.684, p<0.001\right)$ and duration of mother-pup interaction $\left(\mathrm{F}_{1,12}=6.903, p=0.022\right)$, whereas the injection procedure did not influence maternal care (dam sortieinjection: $\mathrm{F}_{1,12}=1.98, p=0.185$; interaction: $\mathrm{F}_{1,12}=1.363$, $p=0.266$; dam-pup interaction-injection: $\mathrm{F}_{1,12}=1.393$, $p=0.261$; interaction: $\mathrm{F}_{1,12}=0.033, p=0.859$; Supplementary Figure S3). Moreover, early-life stress persistently

a

Experiment 2

Stress and daily antalarmin injections

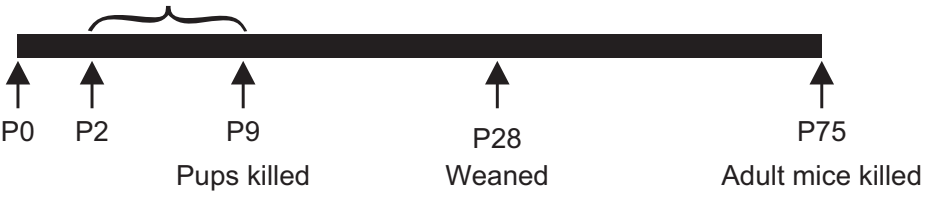

b
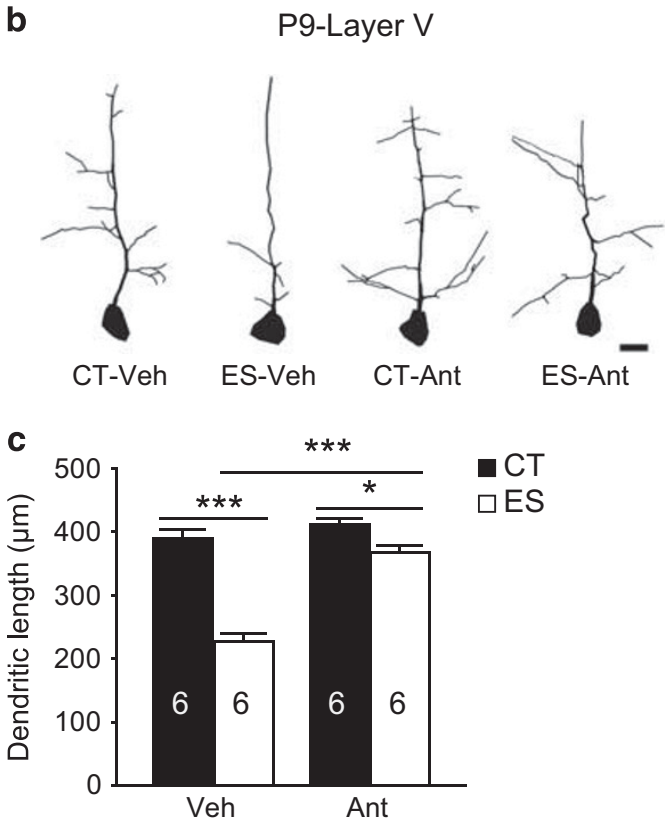

d

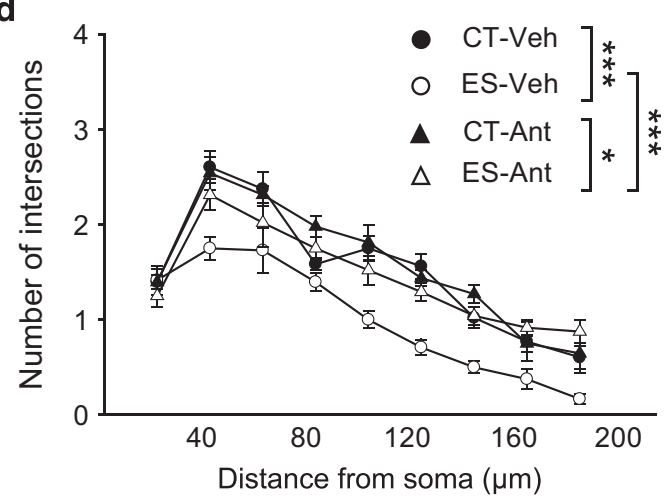

e

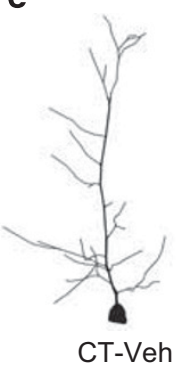

P75-Layer V
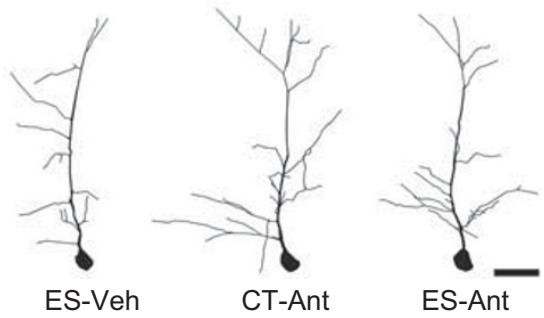

f

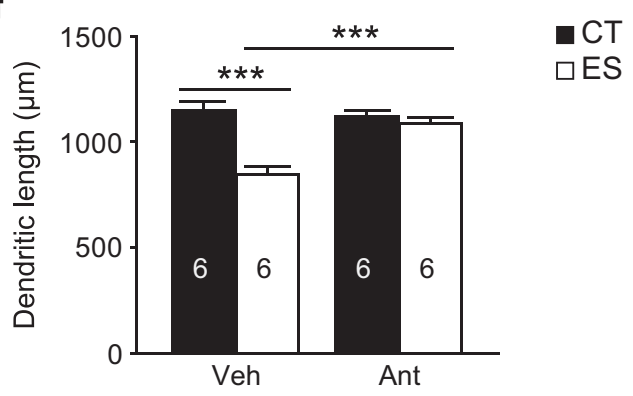

g

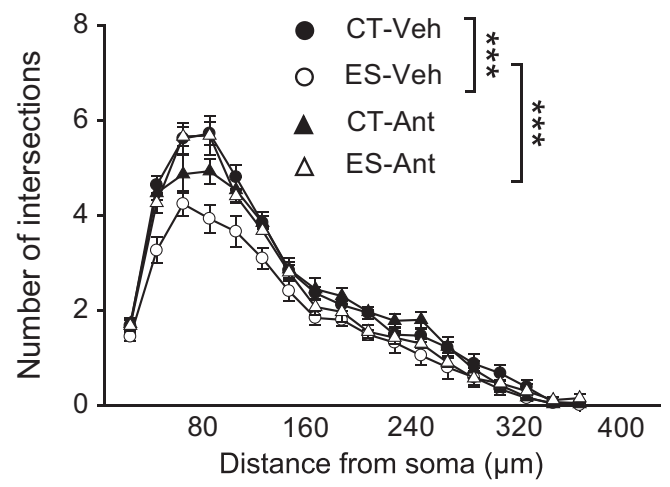

Figure 3 Effects of $C R F$, blockade on early-life stress-induced dendritic abnormalities in ACd layer $\vee$ pyramidal neurons. (a) Schematic of the design of experiment 2. (b) Representative tracings of apical dendrites of ACd layer $\vee$ pyramidal neurons at P9. Scale bar $=20 \mu \mathrm{m}$. (c, d) In vehicle (Veh)-injected pups, early-life stress reduced the length (c) and branching (d) of apical dendrites that were attenuated by blockade of CRF, with antalarmin (Ant). (e) Representative tracings of apical dendrites of ACd layer $\vee$ pyramidal neurons at P75. Scale bar $=50 \mu m$. (f, g) Antalarmin treatment normalized the length ( $\mathrm{f}$ ) and complexity (g) of apical dendrites in stressed adult mice. $* p<0.05$, $* * * * 00.001$. 
inhibited body weight gain (P9: $t_{37}=3.927, p<0.001$; P28-P70: $\left.\mathrm{F}_{1,12}=4.864, p=0.048\right)$, whereas $\mathrm{CRF}_{1}$ blockade during stress exposure increased body weight gain in adolescence and adulthood (P9-stress: $F_{1,66}=60.877$, $p<0.001$; P28-P70-stress: $\mathrm{F}_{1,33}=30.978, p<0.001$; treatment: $F_{1,33}=4.182, p=0.049$; Supplementary Figure S4).

In both neonatal and adult mice, early stressful experience and antalarmin interacted to shape apical dendritic morphology of ACd layer $\mathrm{V}$ pyramidal neurons (P9 length-stress: $\mathrm{F}_{1,20}=106.218, p<0.001$; treatment: $\mathrm{F}_{1,20}=$ 65.408, $p<0.001$; interaction: $\mathrm{F}_{1,20}=35.681, p<0.001$; P9 complexity-stress: $\mathrm{F}_{1,20}=73.492, \quad p<0.001$; treatment: $\mathrm{F}_{1,20}=42.739, \quad p<0.001$; $\quad$ interaction: $\mathrm{F}_{1,20}=26.204$, $p<0.001$; P75 length-stress: $\mathrm{F}_{1,20}=40.62, p<0.001$; treatment: $\mathrm{F}_{1,20}=16.105, p=0.001$; interaction: $\mathrm{F}_{1,20}=26.629$, $p<0.001$; P75 complexity-stress: $\mathrm{F}_{1,20}=51.671, p<0.001$; treatment: $F_{1,20}=13.527, p=0.001$; interaction: $F_{1,20}=$ 32.524, $p<0.001$; Figure $3 \mathrm{~b}$ and e). Consistent with the results of experiment 1, early-life stress decreased the length $\left(p<0.001\right.$, Bonferroni's test) and complexity $\left(\mathrm{F}_{1,10}=84.739\right.$, $p<0.001)$ of apical dendrites in vehicle-injected pups, and this effect persisted to adulthood (length: $p<0.001$, Bonferroni's test; complexity: $\left.\mathrm{F}_{1,10}=54.076, p<0.001\right)$. Although stressed pups treated with antalarmin had reduced apical dendritic length ( $p<0.05$, Bonferroni's test) and complexity $\left(\mathrm{F}_{1,10}=6.672, p=0.027\right)$ compared with antalarmin-injected controls, they had significantly longer $(p<0.001$, Bonferroni's test $)$ and more complex $\left(\mathrm{F}_{1,10}=\right.$ 43.509, $p<0.001)$ dendrites than vehicle-injected stressed pups (Figure $3 \mathrm{c}$ and $\mathrm{d}$ ). In adulthood, antalarmin treatment abolished postnatal stress-induced dendritic regression (ES-Ant vs ES-Veh-length: $p<0.001$, Bonferroni's test; complexity: $\mathrm{F}_{1,10}=36.772, p<0.001$; Figure $3 \mathrm{f}$ and $\mathrm{g}$ ). We also analyzed the number of branch points and the length of apical trunk dendrite and apical branches (Supplementary Table S1). During development and adulthood, early-life stress reduced, whereas antalarmin increased, the number of branch points. Interestingly, the effects of early-life stress and antalarmin were mostly evident on apical dendritic branches but not apical main trunk.

Next, we evaluated the effects of antalarmin treatment on early-life stress-induced apical dendritic spine loss in ACd layer $\mathrm{V}$ pyramidal neurons (Figure $4 \mathrm{a}$ and $\mathrm{d}$ ). In neonatal pups, antalarmin increased the number of spines on apical main dendrites (treatment: $F_{1,20}=20.387, p<0.001$ ) and prevented stress-induced spine loss on apical oblique dendrites (stress: $\mathrm{F}_{1,20}=7.824, p=0.011$; treatment: $\mathrm{F}_{1,20}=$ 11.917, $p=0.003$; interaction: $\mathrm{F}_{1,20}=5.423, p=0.030$; Figure 4b). Detailed analysis showed that early-life stress and antalarmin regulated the number of thin and stubby spines on apical dendrites (main: thin-treatment: $F_{1,20}=$ 15.657, $p=0.001$; oblique: thin-stress: $\mathrm{F}_{1,20}=6.912$, $p=0.016$; treatment: $\mathrm{F}_{1,20}=6.769, \quad p=0.017$; stubbytreatment: $\mathrm{F}_{1,20}=4.497, p=0.047$; Figure $4 \mathrm{c}$ ). In adult mice, antalarmin treatment during postnatal stress exposure prevented the adverse stress effects on spine density on apical main and oblique dendrites (main-stress: $\mathrm{F}_{1,20}=$ 50.781, $p<0.001$; treatment: $\mathrm{F}_{1,20}=14.528, p=0.001$; interaction: $F_{1,20}=28.306, p<0.001$; oblique-stress: $F_{1,20}=$ 25.302, $p<0.001$; treatment: $\mathrm{F}_{1,20}=16.901, p=0.001$; interaction: $F_{1,20}=25.220, p<0.001$; Figure $4 \mathrm{e}$ ). Detailed analysis showed that early-life stress and antalarmin exerted dendritic domain- and spine subtype-specific effects (main: thin-stress: $\mathrm{F}_{1,20}=25.363, p<0.001$; treatment: $\mathrm{F}_{1,20}=$ 7.052, $p=0.015$; interaction: $\mathrm{F}_{1,20}=15.523, \quad p=0.001$; mushroom-stress: $\mathrm{F}_{1,20}=26.851, \quad p<0.001$; oblique: thin-stress: $F_{1,20}=10.519, p=0.004$; interaction: $F_{1,20}=$ 4.624, $\quad p=0.044 ; \quad$ stubby-interaction: $\quad F_{1,20}=8.101$, $P=0.010$; Figure 4f). Consistent with these spine classification data, we further revealed that early-life stress decreased spine length in both neonatal and adult mice, which was prevented by antalarmin treatment. Moreover, antalarmin normalized spine head diameter on apical oblique dendrites in postnatally stressed adult mice (Supplementary Figure S5).

Notably, in both vehicle- and antalarmin-injected stressed pups, GR and MR protein levels in the neocortex and GRs levels in the hippocampus were significantly downregulated (neocortical GR-stress: $\mathrm{F}_{1,20}=23.304, p<0.001$; neocortical MR-stress: $\mathrm{F}_{1,20}=4.374, p=0.049$; hippocampal GRstress: $F_{1,20}=5.490, p=0.030$; Supplementary Figure S6a and $b$ ). In addition, the protein levels of actin, which was used as the loading control, were not altered by early-life stress or antalarmin treatment (Supplementary Figure S6c). These results indicate that systemic antalarmin administration does not abolish hypothalamic-pituitary-adrenal (HPA) activity and stress response in neonatal pups, and that antalarmin prevents early-life stress-evoked structural abnormalities mainly through the blockade of central $\mathrm{CRF}_{1}$.

\section{Blockade of $\mathrm{CRF}_{1}$ Prevents Early-Life Stress-Induced Cognitive Deficits, But Not Anxiety-Related Behavior, in Adult Mice}

Because antalarmin treatment during early-life stress exposure ameliorated the deleterious stress effects on the development and plasticity of dendrites and spines in ACd neurons, we further investigated its impact on postnatal stress-induced behavioral abnormalities in adult mice (Figure 5a). All groups of mice exhibited similar anxietyrelated behavior in the open field arena (Supplementary Figure S7a), whereas early-life stress significantly reduced the number of entries into and time spent in the brightly lit compartment in the light-dark box test (entry-stress: $\mathrm{F}_{1,24}=5.769, p=0.024$; time-stress: $\mathrm{F}_{1,24}=4.4, p=0.047$; Supplementary Figure S7b). Furthermore, stressed mice were less active in the $\mathrm{Y}$-maze apparatus compared with the control groups (distance-stress: $\mathrm{F}_{1,24}=6.714, p=0.016$; arm entry-stress: $\mathrm{F}_{1,24}=4.433, p=0.046$; Supplementary Figure S7c). However, antalarmin had no effect on early-life stress-induced anxiety-related behavior.

Postnatal antalarmin treatment improved spatial working memory performance in the Y-maze test as shown by increased spontaneous alternation rates in antalarmininjected groups $\left(\mathrm{F}_{1,24}=8.359, p=0.008\right)$. In addition, antalarmin treatment normalized stress-increased same arm return ratio (treatment: $\mathrm{F}_{1,24}=8.757, p=0.007$; interaction: $\mathrm{F}_{1,24}=4.663, p=0.041$; Figure $\left.5 \mathrm{~b}\right)$, which reflects certain aspects of attention (Wall and Messier, 2002; Wietrzych et al, 2005). In each sample phase of the temporal order memory test, all groups of mice explored the two copies of an identical object similarly (Supplementary Figure S7d). In the retrieval phase, significant effects of treatment $\left(\mathrm{F}_{1,26}=7.682, p=0.01\right)$ and interaction 
a

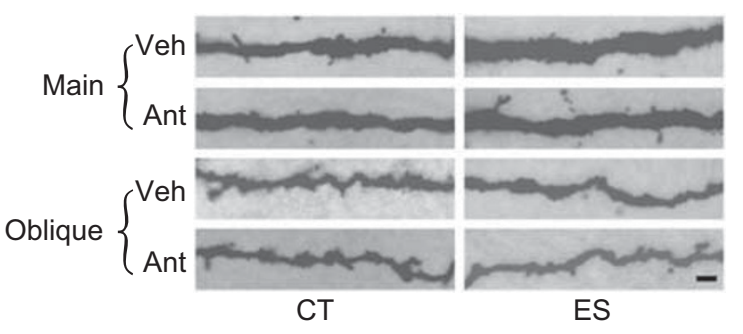

b

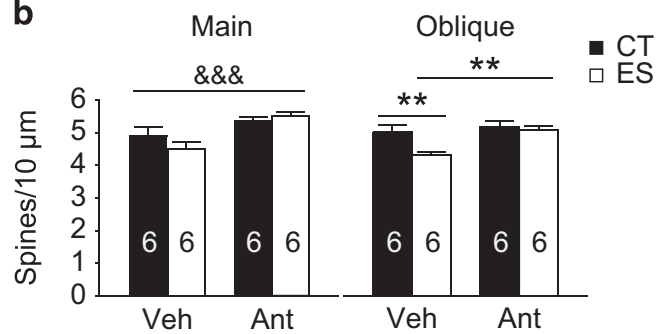

C
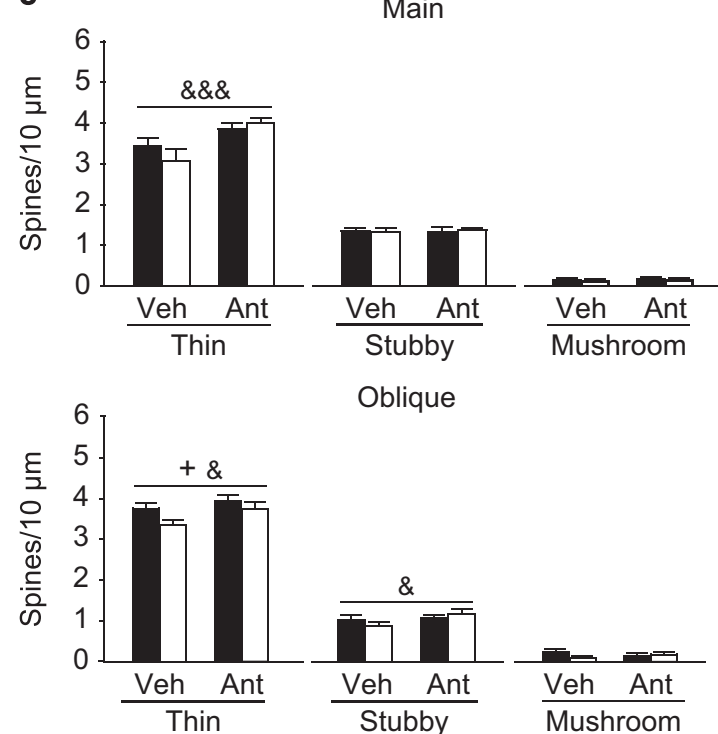

d

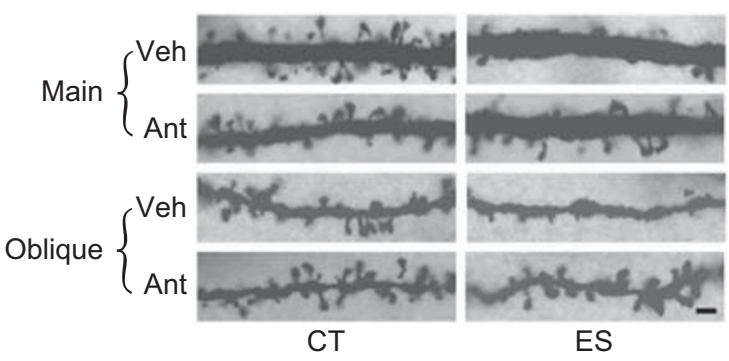

e

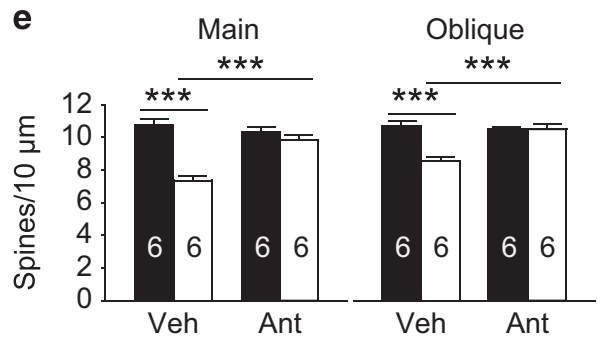

f
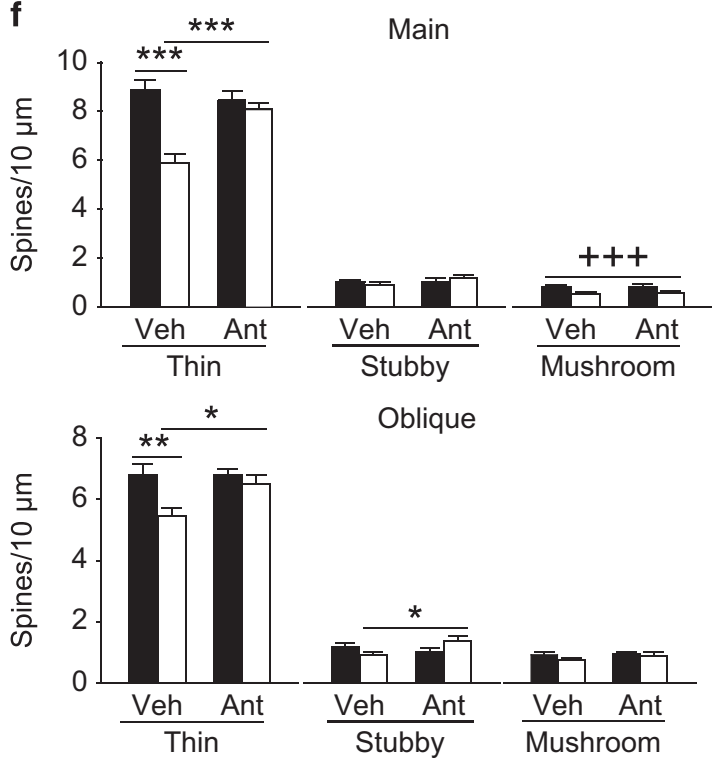

Figure 4 Effects of CRF, blockade on early-life stress-induced spine loss on the apical dendrites of ACd layer $V$ pyramidal neurons. (a) Photomicrographs of apical main and oblique dendrites of ACd layer $V$ pyramidal neurons at P9. Scale bar $=2 \mu \mathrm{m}$. (b) Antalarmin treatment increased total spine density on apical main dendrites and prevented stress-induced spine loss on apical oblique dendrites in neonatal pups. (c) Early-life stress and antalarmin modulated the formation of thin and stubby spines on apical dendrites. (d) Photomicrographs of apical main and oblique dendrites of ACd layer $V$ pyramidal neurons at P75. Scale bar $=2 \mu \mathrm{m}$. (e) Antalarmin treatment during postnatal stress exposure prevented the deleterious stress effects on spine density on apical main and oblique dendrites in adult mice. $(f)$ Early-life stress and antalarmin exerted dendritic compartment- and spine subtype-specific effects in adult mice. $* p<0.05$,

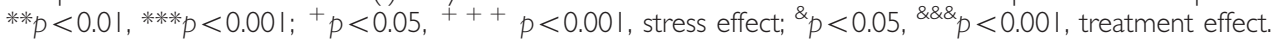

$\left(\mathrm{F}_{1,26}=5.531, p=0.027\right)$ were noticed. All groups of mice, except for stressed mice with vehicle injection, discriminated the object presented least recently from the one presented more recently (CT-Veh: $t_{6}=3.576, p=0.012$; ES-Veh: $t_{7}=0.853, p=0.422$; CT-Ant: $t_{7}=2.582, p=0.036$; ES-Ant: $t_{6}=9.295, p<0.001$; Figure $5 c$ ). Moreover, vehicleinjected stressed mice performed worse than vehicle-treated controls $(p<0.05$, Bonferroni's test $)$. In comparison, stressed mice with antalarmin treatment showed intact temporal order memory and performed significantly better than vehicle-injected stressed mice $(p<0.01$, Bonferroni's test). Taken together, these results imply that blockade of $\mathrm{CRF}_{1}$ during early-life stress exposure specifically prevents stress-evoked impairments in mPFC-dependent cognition but not anxiety-related behavior.

Following behavioral tests, we again measured the length of apical dendrites of ACd layer $\mathrm{V}$ pyramidal neurons and further assessed the correlations between dendritic length and cognitive performance. Consistent with the results of experiment 2, antalarmin treatment prevented early-life stress-induced dendritic shrinkage (total dendritic length-stress: $\mathrm{F}_{1,27}=12.294, p=0.002$; treatment: $F_{1,27}=13.967, p<0.001$; interaction: $F_{1,27}=11.322$, $p=0.002 ; \quad$ complexity-stress: $\mathrm{F}_{1,27}=14.182, \quad p<0.001$; 
a

Experiment 3

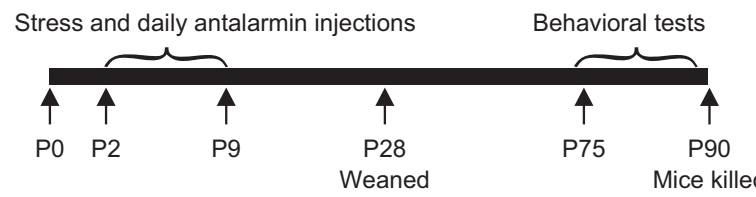

b

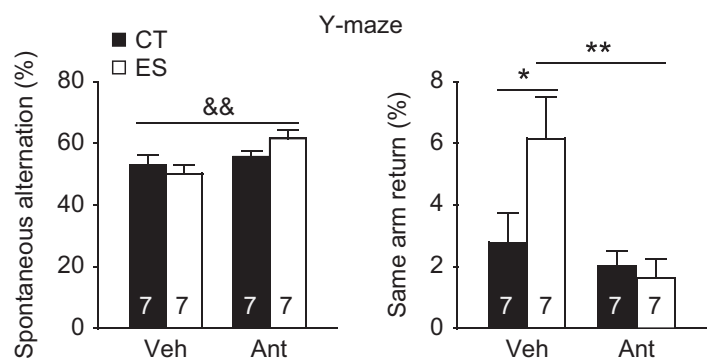

c

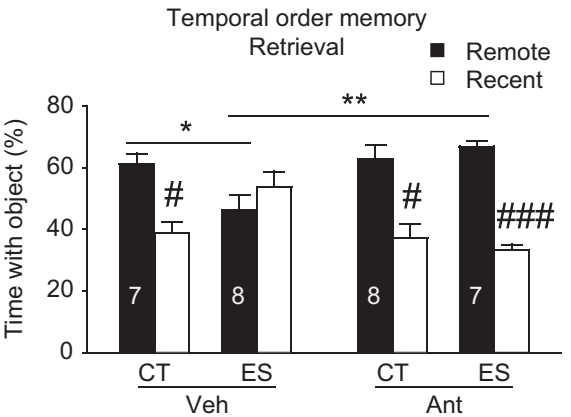

d

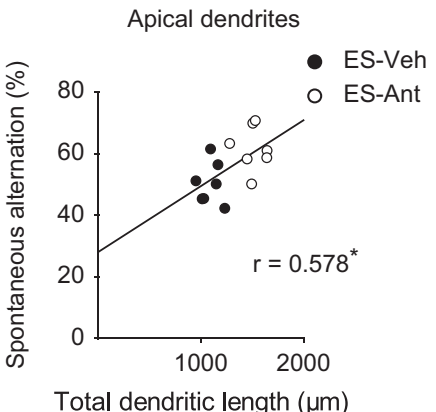

e

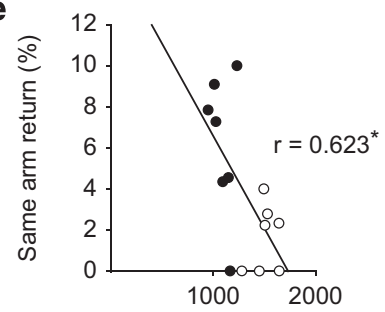

Total dendritic length $(\mu \mathrm{m})$

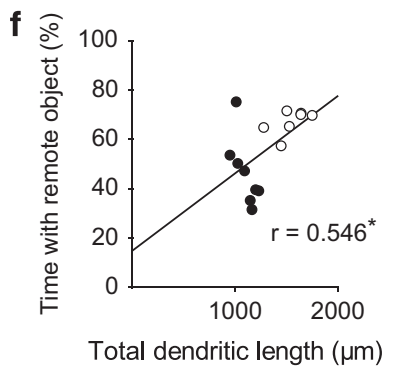

Apical branches

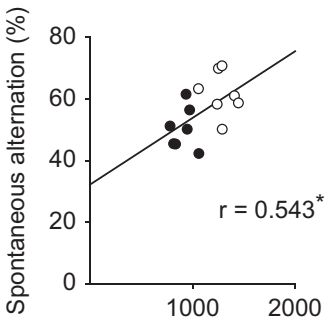

Total branch length $(\mu \mathrm{m})$

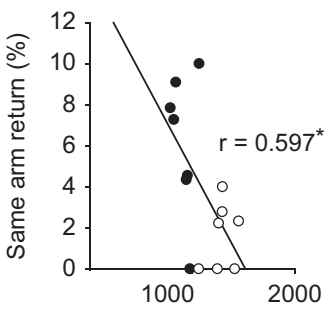

Total branch length $(\mu \mathrm{m})$

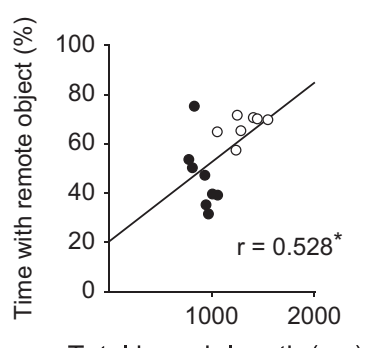

Total branch length $(\mu \mathrm{m})$

Figure 5 Effects of $C R F$, blockade on early-life stress-induced cognitive deficits and correlations between cognitive performance and apical dendritic length of ACd layer V pyramidal neurons in adult mice. (a) Schematic of the design of experiment 3. (b) In the Y-maze test, antalarmin improved spontaneous alternation behavior and normalized stress-increased same arm return ratio. (c) In the retrieval phase of the temporal order memory test, earlylife stressed mice with vehicle injection exhibited impaired performance as indicated by the absence of object discrimination that was restored in antalarmininjected stressed mice. (d) The length of apical dendrites and apical branches of ACd layer $V$ neurons significantly correlated with spontaneous alternation rates in the Y-maze test in stressed groups. (e) Both total dendritic length and total branch length inversely correlated with the ratio of same arm returns in the two stressed groups. Note that these correlations were strengthened after removal of offline outliers whose same arm return ratio was 0 (apical dendrites: $r=-0.722, p<0.00 \mathrm{I}$; apical branches: $r=-0.720, p<0.00 \mathrm{I}$ ). (f) Both total dendritic length and total branch length significantly correlated with temporal order memory performance in the two stressed groups. ${ }^{p} p<0.05,{ }^{* *} p<0.0$ I; ${ }^{\#} p<0.05,{ }^{\# \#} p<0.00$ I for comparisons between the remote and recent objects within the same group; ${ }^{\& \&} p<0.01$, treatment effect.

treatment: $F_{1,27}=13.509, p=0.001$; interaction: $F_{1,27}=$ 15.029, $p<0.001$; total branch length-stress: $\mathrm{F}_{1,27}=$ 13.841, $p=0.001$; treatment: $\mathrm{F}_{1,27}=11.700, p=0.002$; interaction: $F_{1,27}=9.799, p=0.004$; Supplementary Figure $S 8$ ). In the Y-maze test, both total apical dendritic length and apical branch length significantly correlated with spontaneous alternation rates (apical dendrites: $r=0.578$, $p=0.030$; apical branches: $r=0.543, p=0.045$; Figure $5 \mathrm{~d}$ ) and inversely correlated with the ratio of same arm returns (apical dendrites: $r=-0.623, p=0.017$; apical branches: $r=-0.597, p=0.024$; Figure $5 \mathrm{e}$ ) in stressed mice. In the temporal order memory test, significant correlations between dendritic length and time with the remote object in the retrieval phase were revealed in the two stressed groups (apical dendrites: $r=0.546, p=0.035$; apical branches: $r=0.528, p=0.043$; Figure $5 f$ ). In vehicle-injected stressed mice, the extent of dendritic shrinkage predicted the degree of cognitive impairment. In comparison, antalarmin-treated stressed mice with longer apical dendrites showed better cognitive performance. In control mice, we did not observe significant correlations between dendritic length and cognitive performance, except for a significant inverse correlation between apical branch length and same arm return ratio $(r=-0.546, p=0.044)$. These data suggest that dendritic shrinkage, especially the regression of apical dendritic branches, of ACd layer V pyramidal neurons may underlie cognitive deficits in stressed mice.

\section{DISCUSSION}

Animal models of early-life stress provide the opportunity to study experience-dependent neural plasticity and are useful to disentangle the mechanisms of stress-related psychiatric disorders. In this study, we showed that early postnatal stress persistently disrupted the development and 
plasticity of apical dendrites of layer $\mathrm{V}$ pyramidal neurons in ACd. Most importantly, we found that $\mathrm{CRF}_{1}$ blockade during stress exposure ameliorated these region-specific morphological alterations and restored cognitive function, indicating that $\mathrm{CRF}_{1}$ modulates the effects of early-life stress on prefrontal development and function.

\section{The Region-Specific Effects of Early Postnatal Stress Suggest a Sensitive Period for the Development of mPFC Layer V Pyramidal Neurons}

Recent studies have reported that early-life stress alters dendritic morphology and spine density of prefrontal pyramidal neurons (Chocyk et al, 2013; Monroy et al, 2010; Muhammad and Kolb, 2011). However, the results are variable. The discrepancy among these studies may be ascribed to the status of neuroendocrine function upon stress challenge, as stress exposure before, during, or after the stress hyporesponsive period (Schmidt, 2010) may exert distinct effects on the remodeling of dendrites and spines in $\mathrm{mPFC}$ neurons (Bock et al, 2005; Gos et al, 2008). Yet another possibility is that, in these studies, the time window of stress exposure spanned various developmental stages that are different in the expression of synaptic molecules and the degree of connectivity and functionality (Lohmann and Kessels, 2014).

Using a robust and naturalistic mouse model of early-life stress (Rice et al, 2008), we evaluated the spatial and temporal characteristics of the effects of stress exposure around the first postnatal week on the morphology of layers II/III and V pyramidal neurons in ACd and PL. We found that pyramidal neurons in both layers of ACd were affected after stress ended, yet the lasting effects of early-life stress were only present in layer $\mathrm{V}$ pyramidal neurons. In PL, although the stress effects did not persist to adulthood, the short-term influences of early-life stress were more prominent in layer V than in layer II/III neurons. These data indicate that the first postnatal week might be a stresssensitive period for the development of layer V neurons.

During neocortical development, sequentially generated pyramidal neurons migrate in an 'inside-out' pattern, and the upper layer (II/III) neurons are younger than those settled in the lower layers (V and VI) (Franco and Müller, 2013). In addition, the structural changes of layer $\mathrm{V}$ pyramidal neurons precede those of layer II/III neurons in the visual cortex (Miller, 1981). Therefore, the critical periods for dendritic outgrowth and branching in layers II/III and V neurons may overlap only partially, contributing to their differential morphological phenotypes after early postnatal stress exposure. Moreover, we observed that the acute and long-term effects of early-life stress on dendritic development and spine formation in ACd pyramidal neurons were confined to apical dendrites. These layerand dendritic domain-specific effects of early-life stress may be relevant to molecules that show layer-specific expression patterns. For example, the transcription factors Cux1 and Cux2 are specifically expressed in upper layer neurons and regulate the morphological and functional maturation of layer II/III but not layer V neurons (Cubelos et al, 2010). Similarly, another transcription factor Fezf2 is selectively expressed by lower layer neurons and regulates dendrite and spine development in layer $\mathrm{V}$ but not layer II/III neurons (Chen et al, 2005). However, it remains to be studied whether these molecules are involved in early-life stress-induced prefrontal alterations and whether stress mediators, including CRF and $\mathrm{CRF}_{1}$, interact with these molecules to differentially modulate the development and plasticity of neuronal subpopulations in MPFC. In addition, it would also be worthwhile to examine whether stress exposure during later postnatal stages (the second or third postnatal week) would affect upper $v s$ lower layer neurons disparately.

\section{$\mathrm{CRF}_{1}$ Blockade during Stress Exposure Prevents Early-Life Stress-Induced Dendritic Regression and Spine Loss and Restores mPFC-Dependent Cognitive Performance}

CRF and its receptors are key mediators of neuroendocrine, cognitive, and behavioral responses to stress. Once the stressor is perceived, CRF is rapidly released and activates $\mathrm{CRF}_{1}$ that, in turn, interacts with neurotransmitter systems and synaptic molecules to modulate neural circuit development and synaptic plasticity (Andres et al, 2013; Tan et al, 2004; Wang et al, 2013). Using the same stress paradigm, we and others have demonstrated the critical role of the CRF-CRF ${ }_{1}$ system in mediating the effects of earlylife stress on the development, plasticity, and function of the hippocampus. Repeated administration of a $\mathrm{CRF}_{1}$ antagonist antalarmin during stress exposure attenuates hippocampal synaptic abnormalities in stressed pups (Liao et al, 2014), whereas pharmacological blockade or transgenic inactivation of central $\mathrm{CRF}_{1}$ after stress restores hippocampal synaptic plasticity and spatial learning and memory in adult mice (Ivy et al, 2010; Wang et al, 2011). Our present study extended these findings and showed that concurrent antalarmin treatment could attenuate early-life stressevoked apical dendritic regression and spine loss in ACd layer $\mathrm{V}$ pyramidal neurons.

The layer $\mathrm{V}$ pyramidal neurons in ACd integrate widespread inputs from various brain regions (Hoover and Vertes, 2007) and project to multiple subcortical areas, including striatum, amygdala, dorsal raphe, and spinal cord (Gabbott et al, 2005), to facilitate emotional expression, motor coordination, and temporal organization of behavior. In adult mice with early-life stressful experiences and vehicle treatment, mPFC-dependent cognition, including certain aspects of attention (reflected by the percentage of same arm returns) and temporal order memory, was markedly impaired. In contrast, daily antalarmin administration during stress exposure restored cognition in adult mice. Moreover, in stressed mice with vehicle treatment, impaired cognitive performance was closely associated with shrinkage of apical dendrites. These results strengthen the link between dendritic morphology and cognition, and pinpoint the role of the CRF-CRF 1 system in shaping the structure and function of mPFC pyramidal neurons and related neural circuits under stressful situations.

It should be noted that systemic antalarmin administration antagonizes both central and peripheral $\mathrm{CRF}_{1}$. Blockade of $\mathrm{CRF}_{1}$ in the pituitary will disrupt HPA activity and may thus confound the current findings. However, our results indicate that the treatment strategy we applied generally preserved HPA activity and stress response. As shown previously, postnatally stressed animals exhibit 
elevated corticosterone secretion, inhibited body weight gain, and reduced expression levels of GRs and MRs in the hippocampus (Schmidt, 2010). Similarly, we observed that compared with the controls, stressed pups with vehicle or antalarmin treatment had significantly lower body weight and reduced GR and MR protein levels in the neocortex and/or the hippocampus. Therefore, the effects of antalarmin on stress-induced structural alterations and cognitive impairments may be largely attributed to the blockade of central $\mathrm{CRF}_{1}$, instead of attenuated HPA activity by pituitary $\mathrm{CRF}_{1}$ blockade. Nonetheless, future studies using more region-specific approaches are needed to clarify the role of prefrontal $\mathrm{CRF}_{1}$ in early-life stress-associated prefrontal abnormalities.

The molecular mechanisms underlying the effects of $\mathrm{CRF}_{1}$ and early-life stress on prefrontal development and function remain unclear. Previous studies have shown that CRF facilitates the phosphorylation of PKC in PFC slices (Tan et al, 2004), whereas inhibiting PKC activity rescues chronic adult stress-induced apical dendritic spine loss in mPFC neurons and working memory deficits (Hains et al, 2009). Intriguingly, the protein levels of PKC isoforms increase rapidly around the first postnatal week (Roisin and Barbin, 1997). In future studies, the involvement of PKC and other candidate molecules, including nectin-3 that interacts with $\mathrm{CRF}_{1}$ to modulate the negative stress effects on hippocampal plasticity (Wang et al, 2013) as well as glucocorticoids and glutamate receptors, in postnatal stress-induced prefrontal dysfunction should be determined.

\section{Early-Life Stress, Anxiety, and $\mathrm{CRF}_{1}$}

The current data showed that early-life stress-induced anxiety-related behavior was not influenced by systemic antalarmin administration. In comparison, we reported previously that transgenic deletion of forebrain $\mathrm{CRF}_{1}$, which initiates at the end of the second postnatal week, partially prevented the anxiogenic effects of early-life stress in adult mice (Wang et al, 2012). The inconsistency between these studies is likely ascribed to the broad brain regions manipulated by pharmacological blockade compared with the region-specific knockout in conditional $\mathrm{CRF}_{1}$ mutants. As revealed by recent studies, the modulation of anxiety by $\mathrm{CRF}_{1}$ is complicate and delicate: $\mathrm{CRF}_{1}$ in forebrain glutamatergic neurons mediates anxiogenic effects, whereas $\mathrm{CRF}_{1}$ in the globus pallidus and midbrain dopaminergic neurons exerts anxiolytic effects (Refojo et al, 2011; Sztainberg et al, 2011). Alternatively, these results may indicate that the timing of $\mathrm{CRF}_{1}$ inactivation is crucial for attenuating the effects of early-life stress on anxiety-related behavior.

\section{Clinical Implications}

Early-life stress is a risk factor for psychiatric disorders including schizophrenia and depression, with prefrontal dysfunction as a shared hallmark of these disorders (Goto et al, 2010). Notably, in schizophrenia patients, the dendritic complexity of PFC layer V pyramidal neurons is markedly reduced (Black et al, 2004). Our findings that early postnatal stress lastingly impairs structural plasticity of ACd layer $\mathrm{V}$ neurons may therefore have clinical relevance. However, because of interspecies differences in the anatomical and functional organizations and postnatal development of PFC (Uylings et al, 2003; Van Eden and Uylings, 1985), the translation of these findings to clinical situations is challenging. Further studies in non-human primates are warranted to validate our data and evaluate the therapeutic potential of $\mathrm{CRF}_{1}$ antagonists in early-life stressinduced prefrontal abnormalities.

In summary, our study reveals the spatial and temporal features of the influences of early postnatal stress on the development of mPFC pyramidal neurons, and highlights $\mathrm{CRF}_{1}$ as a key molecule in modulating the detrimental stress effects on the structural organizations of mPFC and mPFCdependent cognition.

\section{FUNDING AND DISCLOSURE}

The authors declare no conflict of interest.

\section{ACKNOWLEDGEMENTS}

We thank Professor Yi Rao and Dr Xian Zhang for the use of the Neurolucida system. This work was supported by the National Natural Science Foundation of China (grant numbers 81171284 and 81301152), the International Brain Research Organization, the Research Fund for the Doctoral Program of Higher Education of China (number 20120001110046), and Beijing Natural Science Foundation (number 7133259).

\section{REFERENCES}

Alon T, Zhou L, Pérez CA, Garfield AS, Friedman JM, Heisler LK (2009). Transgenic mice expressing green fluorescent protein under the control of the corticotropin-releasing hormone promoter. Endocrinology 150: 5626-5632.

Andres AL, Regev L, Phi L, Seese RR, Chen Y, Gall CM et al (2013). NMDA receptor activation and calpain contribute to disruption of dendritic spines by the stress neuropeptide CRH. J Neurosci 33: $16945-16960$.

Barker GR, Bird F, Alexander V, Warburton EC (2007). Recognition memory for objects, place, and temporal order: a disconnection analysis of the role of the medial prefrontal cortex and perirhinal cortex. J Neurosci 27: 2948-2957.

Black JE, Kodish IM, Grossman AW, Klintsova AY, Orlovskaya D, Vostrikov V et al (2004). Pathology of layer V pyramidal neurons in the prefrontal cortex of patients with schizophrenia. Am J Psychiatry 161: 742-744.

Bock J, Gruss M, Becker S, Braun K (2005). Experience-induced changes of dendritic spine densities in the prefrontal and sensory cortex: correlation with developmental time windows. Cereb Cortex 15: 802-808.

Bradley RG, Binder EB, Epstein MP, Tang Y, Nair HP, Liu W et al (2008). Influence of child abuse on adult depression: moderation by the corticotropin-releasing hormone receptor gene. Arch Gen Psychiatry 65: 190-200.

Chen JG, Rasin MR, Kwan KY, Šestan N (2005). Zfp312 is required for subcortical axonal projections and dendritic morphology of deep-layer pyramidal neurons of the cerebral cortex. Proc Natl Acad Sci USA 102: 17792-17797.

Chocyk A, Bobula B, Dudys D, Przyborowska A, MajcherMaślanka I, Hess G et al (2013). Early-life stress affects the structural and functional plasticity of the medial prefrontal cortex in adolescent rats. Eur J Neurosci 38: 2089-2107. 
Cubelos B, Sebastián-Serrano A, Beccari L, Calcagnotto ME, Cisneros E, Kim S et al (2010). Cux1 and Cux2 regulate dendritic branching, spine morphology, and synapses of the upper layer neurons of the cortex. Neuron 66: 523-535.

Cutajar MC, Mullen PE, Ogloff JR, Thomas SD, Wells DL, Spataro J (2010). Schizophrenia and other psychotic disorders in a cohort of sexually abused children. Arch Gen Psychiatry 67: 1114-1119.

Evans GW, Schamberg MA (2009). Childhood poverty, chronic stress, and adult working memory. Proc Natl Acad Sci USA 106: $6545-6549$.

Franco SJ, Müller U (2013). Shaping our minds: stem and progenitor cell diversity in the mammalian neocortex. Neuron 77: 19-34.

Gabbott PL, Warner TA, Jays PR, Salway P, Busby SJ (2005). Prefrontal cortex in the rat: projections to subcortical autonomic, motor, and limbic centers. J Comp Neurol 492: 145-177.

Gos T, Bock J, Poeggel G, Braun K (2008). Stress-induced synaptic changes in the rat anterior cingulate cortex are dependent on endocrine developmental time windows. Synapse 62: 229-232.

Goto Y, Yang CR, Otani S (2010). Functional and dysfunctional synaptic plasticity in prefrontal cortex: roles in psychiatric disorders. Biol Psychiatry 67: 199-207.

Hains $\mathrm{AB}, \mathrm{Vu}$ MA, Maciejewski PK, van Dyck CH, Gottron M, Arnsten AF (2009). Inhibition of protein kinase C signaling protects prefrontal cortex dendritic spines and cognition from the effects of chronic stress. Proc Natl Acad Sci USA 106: 17957-17962.

Hanson JL, Chung MK, Avants BB, Rudolph KD, Shirtcliff EA, Gee JC et al (2012). Structural variations in prefrontal cortex mediate the relationship between early childhood stress and spatial working memory. J Neurosci 32: 7917-7925.

Harris KM, Jensen FE, Tsao B (1992). Three-dimensional structure of dendritic spines and synapses in rat hippocampus (CA1) at postnatal day 15 and adult ages: implications for the maturation of synaptic physiology and long-term potentiation. J Neurosci 12: $2685-2705$

Holtmaat A, Svoboda K (2009). Experience-dependent structural synaptic plasticity in the mammalian brain. Nat Rev Neurosci 10: 647-658.

Hoover WB, Vertes RP (2007). Anatomical analysis of afferent projections to the medial prefrontal cortex in the rat. Brain Struct Funct 212: 149-179.

Ivy AS, Rex CS, Chen Y, Dubé C, Maras PM, Grigoriadis DE et al (2010). Hippocampal dysfunction and cognitive impairments provoked by chronic early-life stress involve excessive activation of CRH receptors. J Neurosci 30: 13005-13015.

Kalsbeek A, Voorn P, Buijs RM, Pool CW, Uylings HB (1988). Development of the dopaminergic innervation in the prefrontal cortex of the rat. J Comp Neurol 269: 58-72.

Kühne C, Puk O, Graw J, Hrabě de Angelis M, Schütz G, Wurst W et al (2012). Visualizing corticotropin-releasing hormone receptor type 1 expression and neuronal connectivities in the mouse using a novel multifunctional allele. J Comp Neurol 520: $3150-3180$.

Liao XM, Yang XD, Jia J, Li JT, Xie XM, Su YA et al (2014). Blockade of corticotropin-releasing hormone receptor 1 attenuates early-life stress-induced synaptic abnormalities in the neonatal hippocampus. Hippocampus 24: 528-540.

Lohmann C, Kessels HW (2014). The developmental stages of synaptic plasticity. J Physiol 592: 13-31.

Martin KP, Wellman CL (2011). NMDA receptor blockade alters stress-induced dendritic remodeling in medial prefrontal cortex. Cereb Cortex 21: 2366-2373.

McEwen BS, Morrison JH (2013). The brain on stress: vulnerability and plasticity of the prefrontal cortex over the life course. Neuron 79: 16-29.
Miller M (1981). Maturation of rat visual cortex. I. A quantitative study of Golgi-impregnated pyramidal neurons. J Neurocytol 10: 859-878.

Molet J, Maras PM, Avishai-Eliner S, Baram TZ (2014). Naturalistic rodent models of chronic early-life stress. Dev Psychobiol 56: $1675-1688$

Monroy E, Hernández-Torres E, Flores G (2010). Maternal separation disrupts dendritic morphology of neurons in prefrontal cortex, hippocampus, and nucleus accumbens in male rat offspring. J Chem Neuroanat 40: 93-101.

Muhammad A, Kolb B (2011). Maternal separation altered behavior and neuronal spine density without influencing amphetamine sensitization. Behav Brain Res 223: 7-16.

Nugent NR, Tyrka AR, Carpenter LL, Price LH (2011). Geneenvironment interactions: early life stress and risk for depressive and anxiety disorders. Psychopharmacology (Berl) 214: 175-196.

Paxinos G, Halliday G, Watson C, Koutcherov Y, Wang HQ (2007). Atlas of the Developing Mouse Brain: At E17. 5, P0, and P6. Academic Press: London, UK.

Portera-Cailliau C, Pan DT, Yuste R (2003). Activity-regulated dynamic behavior of early dendritic protrusions: evidence for different types of dendritic filopodia. J Neurosci 23: 7129-7142.

Refojo D, Schweizer M, Kuehne C, Ehrenberg S, Thoeringer C, Vogl AM et al (2011). Glutamatergic and dopaminergic neurons mediate anxiogenic and anxiolytic effects of CRHR1. Science 333: 1903-1907.

Rice CJ, Sandman CA, Lenjavi MR, Baram TZ (2008). A novel mouse model for acute and long-lasting consequences of early life stress. Endocrinology 149: 4892-4900.

Rissman RA, Staup MA, Lee AR, Justice NJ, Rice KC, Vale W et al (2012). Corticotropin-releasing factor receptor-dependent effects of repeated stress on tau phosphorylation, solubility, and aggregation. Proc Natl Acad Sci USA 109: 6277-6282.

Roisin MP, Barbin G (1997). Differential expression of PKC isoforms in hippocampal neuronal cultures: modifications after basic FGF treatment. Neurochem Int 30: 261-270.

Schmidt MV (2010). Molecular mechanisms of early life stresslessons from mouse models. Neurosci Biobehav Rev 34: 845-852.

Spruston N (2008). Pyramidal neurons: dendritic structure and synaptic integration. Nat Rev Neurosci 9: 206-221.

Sztainberg Y, Kuperman Y, Justice N, Chen A (2011). An anxiolytic role for CRF receptor type 1 in the globus pallidus. J Neurosci 31 17416-17424.

Tan H, Zhong P, Yan Z (2004). Corticotropin-releasing factor and acute stress prolongs serotonergic regulation of GABA transmission in prefrontal cortical pyramidal neurons. J Neurosci 24: 5000-5008.

Uylings HB, Groenewegen HJ, Kolb B (2003). Do rats have a prefrontal cortex? Behav Brain Res 146: 3-17.

Van De Werd HJ, Rajkowska G, Evers P, Uylings HB (2010). Cytoarchitectonic and chemoarchitectonic characterization of the prefrontal cortical areas in the mouse. Brain Struct Funct 214: 339-353.

Van Eden CG (1986). Development of connections between the mediodorsal nucleus of the thalamus and the prefrontal cortex in the rat. J Comp Neurol 244: 349-359.

Van Eden CG, Uylings HB (1985). Cytoarchitectonic development of the prefrontal cortex in the rat. J Comp Neurol 241: 253-267.

Verwer RW, Van Vulpen EH, Van Uum JF (1996). Postnatal development of amygdaloid projections to the prefrontal cortex in the rat studied with retrograde and anterograde tracers. J Comp Neurol 376: 75-96.

Wall PM, Messier C (2002). Infralimbic kappa opioid and muscarinic M1 receptor interactions in the concurrent modulation of anxiety and memory. Psychopharmacology (Berl) 160: 233-244.

Wang XD, Labermaier C, Holsboer F, Wurst W, Deussing JM, Müller MB et al (2012). Early-life stress-induced anxiety-related 
behavior in adult mice partially requires forebrain corticotropinreleasing hormone receptor 1. Eur J Neurosci 36: 2360-2367.

Wang XD, Rammes G, Kraev I, Wolf M, Liebl C, Scharf SH et al (2011). Forebrain $\mathrm{CRF}_{1}$ modulates early-life stress-programmed cognitive deficits. J Neurosci 31: 13625-13634.

Wang XD, Su YA, Wagner KV, Avrabos C, Scharf SH, Hartmann J et al (2013). Nectin-3 links CRHR1 signaling to stress-induced memory deficits and spine loss. Nat Neurosci 16: 706-713.

Wellman CL (2001). Dendritic reorganization in pyramidal neurons in medial prefrontal cortex after chronic corticosterone administration. J Neurobiol 49: 245-253.
Wietrzych M, Meziane H, Sutter A, Ghyselinck N, Chapman PF, Chambon $\mathrm{P}$ et al (2005). Working memory deficits in retinoid X receptor gamma-deficient mice. Learn Mem 12: 318-326.

Zhang J, Miller MI, Plachez C, Richards LJ, Yarowsky P, van Zijl P et al (2005). Mapping postnatal mouse brain development with diffusion tensor microimaging. Neuroimage 26: 1042-1051.

Zhang ZW (2004). Maturation of layer V pyramidal neurons in the rat prefrontal cortex: intrinsic properties and synaptic function. J Neurophysiol 91: 1171-1182.

Supplementary Information accompanies the paper on the Neuropsychopharmacology website (http://www.nature.com/npp) 